Rav, Chit. Pediatr. 59 \{6\}; 358-363, 1988

\title{
Aspectos clínicos del cáncer tiroideo en niños
}

\author{
Dra. Martha Eggets M. ${ }^{1}$; Dr. Francisco Beas F. $^{3}$; Dr. Jorge Las Heras B. ${ }^{3}$; Dra. Amanda Cort ínez R. ${ }^{2}$; \\ Dra. Cecilia Hentíquez del V. ${ }^{1}$; Dra. Elena Kakarieka $W^{3}$

\section{Clinical aspects of thyroid carcinoma in children}

Nine patients with thyroid carciroma, 4 boys and 5 girls, aged 3 to 16 years are described. Their clinical signs went on from hard goiter, through those of mild symptoms of local compression, to evidence of metastases. Thy roid function was normal in these patients and thyroid scintigraphic scans revealed focal low or absent radio iodine uptake. The pathologic study revealed in all them differenciated thyroid carcinomas: 4 papillary cancers associated to chronic thyroidits in 3; 3 cases of papillar-folicular carcinomas and 2 of medullar carcinomas without familiar antecedents. The treatment of choice was total thyroidectomy, for possible multifocal compromise, together with affected adjacent lymph nodes remotion. Postoperative thyroid hormone treatment at TSH suppressive dose was also indicated. Post operative evolution was satisfactory, but secondary hypoparathyroidism ocurred in 3 patients. Early diagnosis of thyroid carcinoma affords relatively good prognosis.

(Key words: thyroid neoplasms, thyroidectomy, thyroiditis, thyroid gland, thyroid diseases).

El cáncer tiroideo es relativamente poco frecuente en la niffez, representando el $1,5 \%$ de los tumores de la infancia ${ }^{1}$. La mayoría corresponde a tipos histológicos bien diferenciados, por lo que su crecimiento puede ser lento y no comprometer la función tiroidea. Sin embargo la mitad de los pacientes ya presentan metástasis en los gan.

1. Servicio de Endocrinología y Genética Infantil, Hosta] Paula Jaraquemada, Instinuto de Investigaciones Clínicas.

2. Instituto de Investigaciones Clinicas, Facultad de Medicina, Unwersidad de Chile, Hospital Panla Jaraquemada.

3. Unidad de Patología Pediátrica, Servicio Anatomja Patológica, Hospital Paula Jaraquemada. glios cervicales en el momento del diagnóstico inicial y 10\% consulta por compromiso metastásico alejado, especialmente pulmonar u óseo ${ }^{2}$. Su evolución, tratamiento y pronóstico dependen del tipo histológico, siendo los más diferenciados, con tratamiento bien llevado, de relativo mejor pronóstico.

\section{MATERIAL Y METODO}

Se presentan ocho niños con cáncer de tiroides estudiados en el Servicio de Endocrinología Infantil del Hospital Paula Jaraquemada y uno fallecido en el Servicjo de Pediatría cuyo diagnóstico sólo se realizó con la autopsia. Cada paciente fue sometido a estudio clínico, incluyendo antecedentes familiares, personales y exámenes de laboratorio de tipo general: hemograma, velocidad de sedimentación globular, calcemia $y$ 
fosfemia, radiografía de carpo para evaluar edad ósea; radiografía de cuello con tếcnica de partes blandas y radiografía de tórax. El estudio endocrinológico consistió en determinación de hormonas tiroidea y tiroestimulante, por método de radioinmunoanátisis; detección de anticuerpos antitiroideos, antimicrosómicos y antitiroglobulina, por técrica de hemaglutinación (Sera-Tek) y cintigrafía tiroidea con Captación de $\mathrm{I}_{131}$ pre $y$ postoperatoria. (Servicio de Medicina Nuclear del Hospital del Salvador). La exploración sistémica con $I_{131}$ postoperatoria sólo se efectuó en 5 pacientes. En 4 pacientes se efectuó punción de nódulo tiroideo mediante técnica de aguja fina y estudio citológico con tinción de Papanicolau. El estudio anatomopatológico se hizo mediante cortes histológicos teñidos con hematoxilina y eosina, tricrómioo de Masson y detección de amiloide.

\section{RESULTADOS}

La edad fluctuó entre los 3 años y los 16 años y en cinco pacientes era de 10 o menos años. $\mathrm{La}$ distribución por sexo fue $\mathrm{M}: \mathrm{F}=5: 4$. El motivo de consulta fue bocio o nódulo cervical, detectados por el paciente o sus familiares, sólo en cuatro casos; en otros tres éstos fueron hallazgos de examen médico motivado por otra causa. En dos niños el estudio fue motivado por afecciones secundarias a metástasis: uno presentó laringitis obstructiva debida a compresión por adenopatía metastásica y el otro neumopatía bilateral, falleciendo 2 meses después con metástasis múltiples pulmonares y de otros parénquimas comprobadas en la autopsia. Los sintomas de compresión local se interrogaron en forma dirigida, encontrándose en cinco pacientes, siendo más frecuente la disfonía intermitente. El tiempo de evolución previo a la primera consulta fue aparentemente corto, no mayor de 3 meses. En los antecedentes familiares tres pacientes tenian familiares de primero y segundo grado con afecciones tiroideas diversas, que incluían un hermano con hipotiroidismo congénito. Además destacó un paciente con cáncer tiroideo de tipo mix to; tenía tres familiares cercanos con diferentes tumores cancerosos. Ningún paciente recibió tratamiento previo con hormona tirojdea por bocio: en seis por haberse planteado la posibilidad de neoplasia en el consultorio. De los tres restantes, una niffa fue referida desde cirugia infantil después de haberse resecado un nódulo cervical, con diagnóstico preoperatorio de quiste del conducto tirogloso, que en la biopsia resultó ser un cáncer medular. Otro paciente fue referido de provincia luego de extirpársele una adenopatía que producía compresión laringotráqueal cuya biopsia mostró evidencias de metástasis de cáncer tiroideo papilar. Finalmente, en el paciente fallecido, el diagnóstico no se hizo en vida; tenía daño neurológico severo que ingresó por neumopatía bilateral que no respondió a diversos esquemas terapéuticos y aparentemente no presentaba aumento del tamaño tíroideo.

En el examen físico se encontraron ganglios cervicales pequeños en cuatro pacientes. El resto del examen fue habitualmente normal, excepto en el primer paciente, el que tenía, además del bocio nodular, un aspecto parecido al $S$. de Marfán y nódulos pequeños múltiples en párpados, labios y lengua (figura 1).

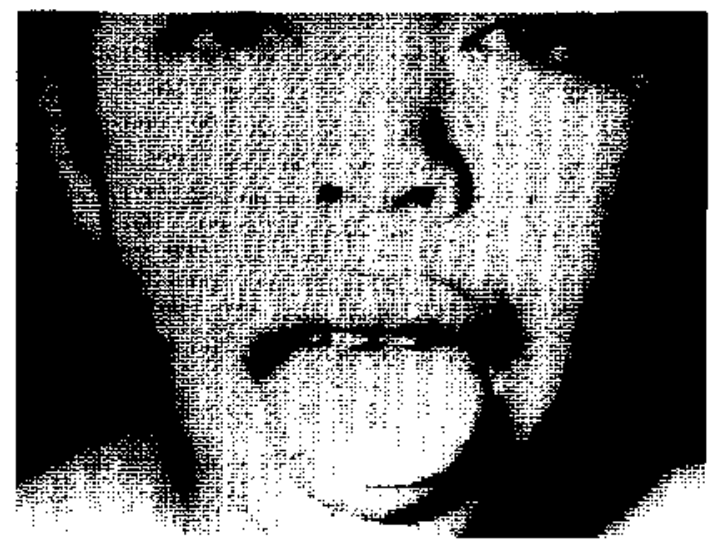

Figura 1: Paciente portador de cáncer tiroideo tipo medular que presenta múltiples neuromas en labios y lengua.

El estudio de función tiroidea de estos pacien. tes fue normal. La cintigrafía tiroidea reveló en algunos pacientes una zona sin captación de $I_{131}$, ("nódulo frío"). En los restantes la captación fue deficiente e irregular. Los exámenes generales fueron normales.

Entre los hallazgos operatorios predominó el bocio nodular, de consistencia dura, siempre adherido a la tráquea y en algunos casos con infiltración a las estructuras vecinas. Se efectuó tiroidectomia total en todos los casos menos en una paciente en la que se hizo tiroidectomía subtotal. El estudio anatomopatológico reveló carcinoma diferenciado en todos los casos. En cuatro pacientes se identificó cáncer de tipo papilar (figura 2) con compromiso multifocal de la glándula, en tres cáncer mixto (papilar-folicular) y en dos cáncer medular (figura 3). De cuatro 


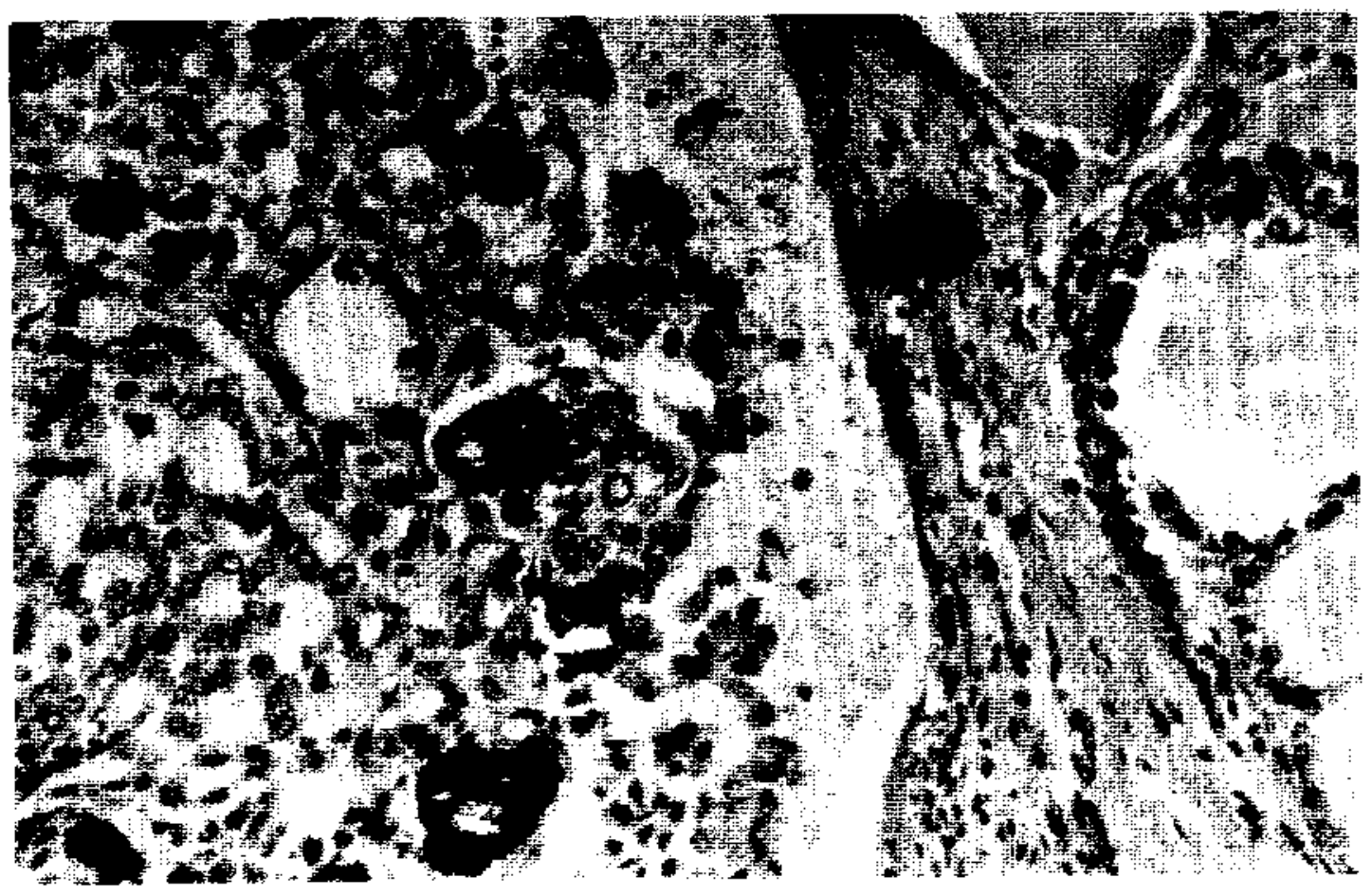

Figura 2: Microfotografía demostrando un área de carcinoma tiroideo tipo papilar, con presencia de los característicos cuerpos de psammoma.

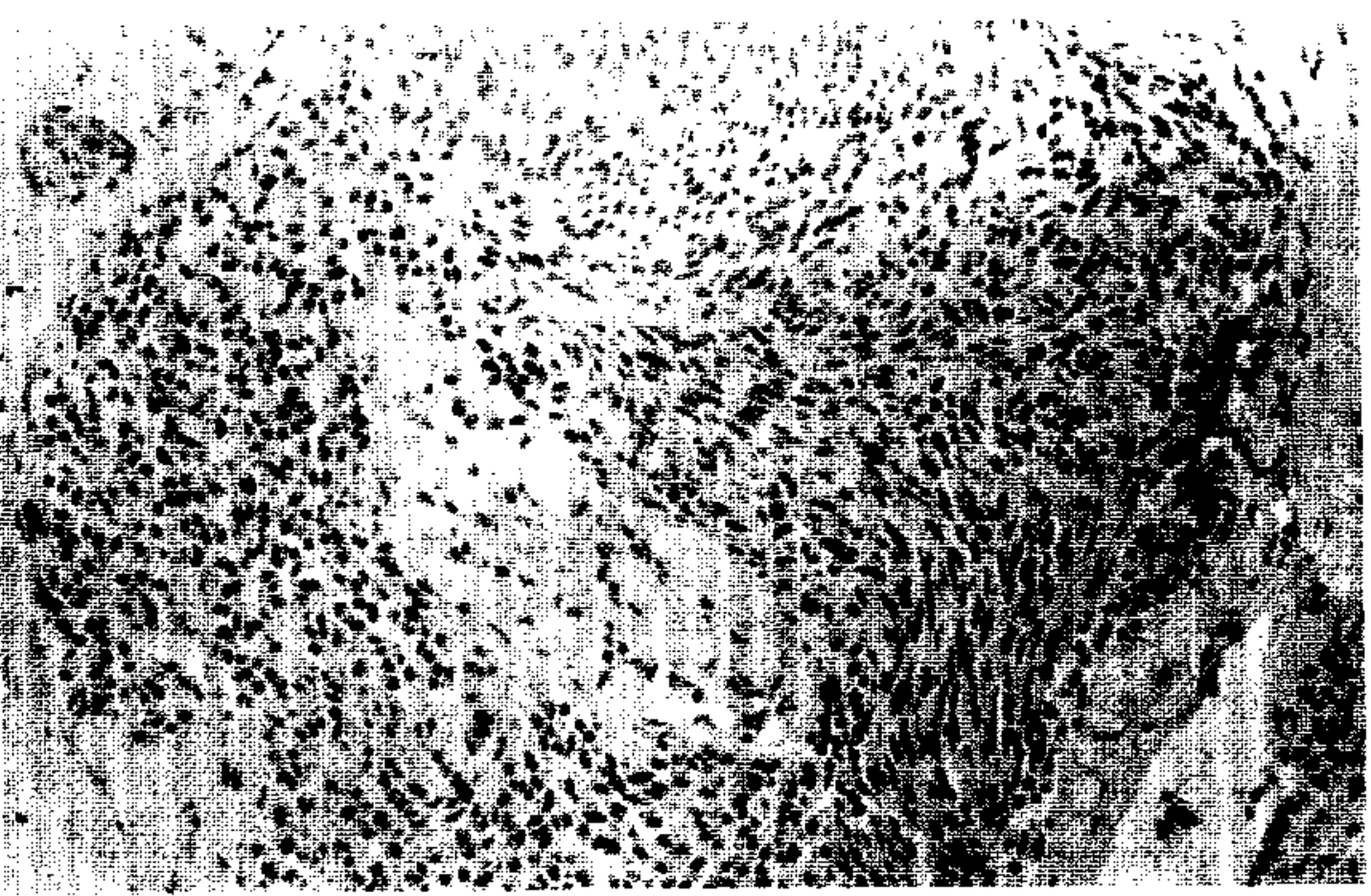

Figura 3: Microfotografía de un nódulo de carcinoma tiroideo tipo medular, compuesto por células redondas o poligonales con núcleos pequeños y uniformes. 
pacientes con cáncer papilar, tres presentaban además signos histológicos de tiroiditis crónica. En cinco pacientes se encontraron ganglios cervicales que fueron extirpados, encontrándose metástasis en cuatro casos ( 3 cánceres papilares y 1 mix to). El paciente cuyo diagnóstico se hizo en autopsia tenía cáncer de tipo mix to y metástasis múltiples en los pulmones, bazo, hígado, riñones (figura 4), ganglios cervicales y mediastínicos.

El estudio de captación tiroidea postoperatoria evidenció tejido remanente en 5 casos, los que fueron tratados con $I_{131}$. Tres pacientes su- frieron hipoparatiroidismo secundario definitivo como complicación operatoria. No hubo casos con lesión del nervio recurrente, ni otro tipo de complicaciones.

Los sobrevivientes ( 8 de 9) están siendo controlados en forma periódica. Se les mantiene con tiroxina en dosis frenadoras de TSH. Los tres pacientes con hipoparatiroidismo reciben dosis altas variables de vitamina $\mathrm{D}_{2}$ y calcio oral, con buena respuesta, observándose tendencia a la hipocalcemia sólo en situaciones de extremo apremio.

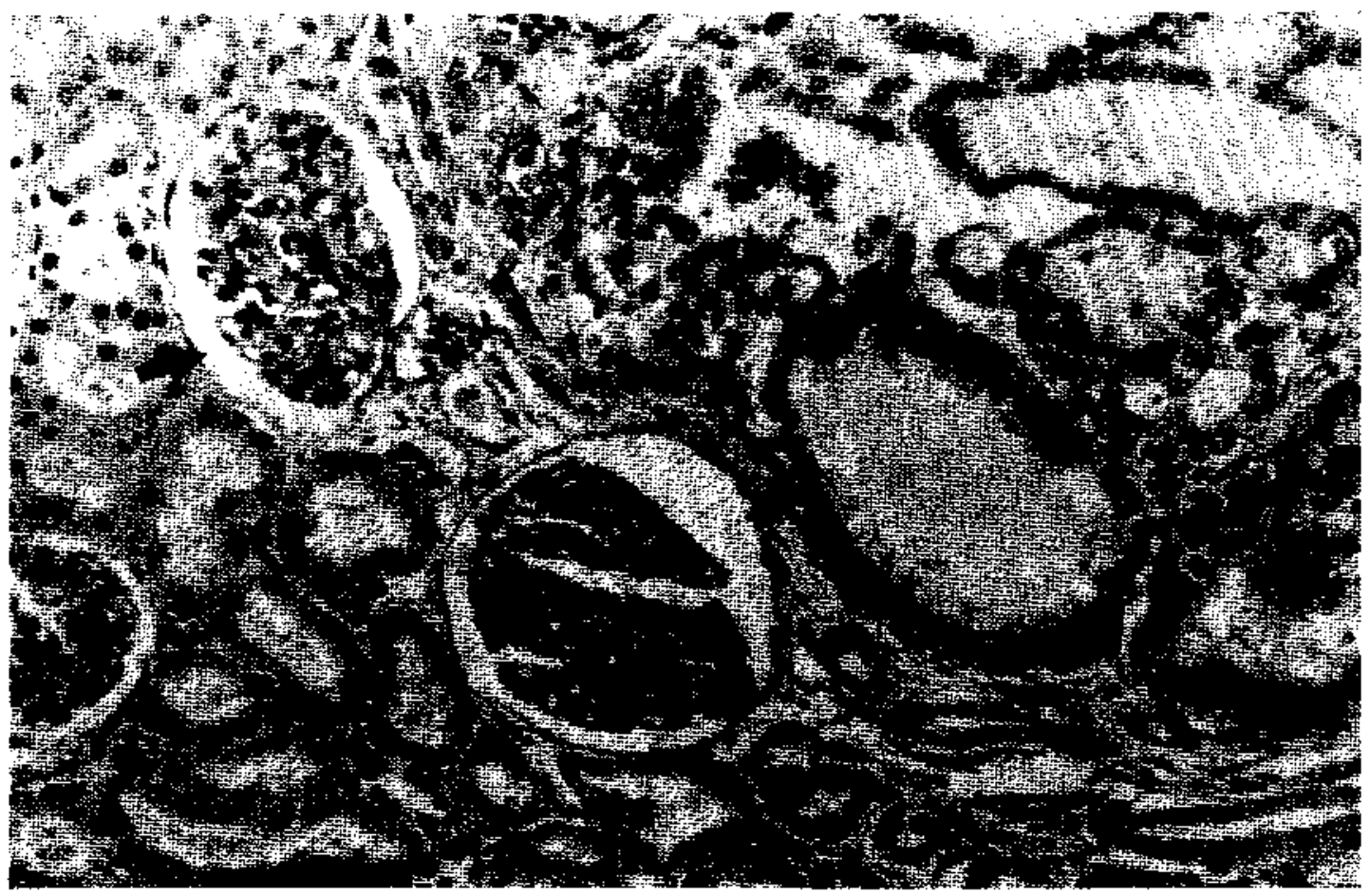

Figura 4: Microfotografía ilustrando la metástasis renal de un carcinoma tiroideo tipo mix to. Se obscrva la presencia de tejido renal con glomérulos (flecha) y un área bien definida de tumor.

\section{DISCUSION}

Los tumores tiroideos, benignos y makignos, son poco frecuentes en el niño. En años recientes se ha destacado el aumento de la incidencia de cáncer tiroideo en niños que han sido sometidos a irradiación terapéutica o accidental ${ }^{3,4}$.

El cáncer tiroideo puede presentarse a cualquier edad, aun en el periodo de recién nacido, pero su incidencia aumenta con cada década de vida. En nuestros pacientes el promedio de edad fue de 9,3 años.
En el niño los tumores de la glándula tiroidea son de curso más benigno que en el adulto. Entre los carcinomas predomina la variedad papilar y el carcinoma anaplástico es muy excepcional. Aunque clásicamente se describe un predominio del sexo femenino de $3: 1^{5}$, de los nueve pacientes estudiados por nosotros, cinco eran mujeres y cuatro hombres.

La forma clinica más común de presentación es el aumento de tamaño del tiroides localizado - difuso, o la presencia de un nódulo de consistencia aumentada. Las adenopatías cervica- 
vicales ocurren en aproximadamente $40 \%$ de los casos publicados. Nosotros pensamos que en cualquier niño con nôdulo tiroideo o bocio con adenopatía cervical la conducta debe ser agresiva y proceder a la brevedad con el estudio diagnósti. co y el tratamiento adecuado. También pueden presentarse metástasis pulmonares ${ }^{7}$ con caracteristicas radiológicas de densidades miliares, que pueden confundirse con tuberculosis, como se observó en uno de nuestros pacientes.

La disfonía por parálisis laríngea presente en tres de nuestros pacientes puede ser el primer motivo de consulta o un hallazgo concomitante con la masa tiroidea. Este síntoma sugiere la extensión del tumor a la laringe o a los nervios laríngeos. La disfagia, observada en uno de nuestros pacientes, puede ser otro sintoma, como manifestación de compresión local o de infiltración tumoral del esófago?

El cáncer de tiroides también se ha observado en tiroides aberrantes o remanentes tiroideos, ya sean éstos linguales o del conducto tirogloso ${ }^{8,9}$. La aplasia de un lóbulo tiroideo es muy rara, pero se ha descrito un aumento de la incidencia del cáncer en esta anomalía ${ }^{10}$. En nuestra serie no observamos ningún caso con anomalias de\} desarrollo tiroideo.

El carcinoma medular del tiroides es raro $(7 \%)$; sin embargo se diagnosticó en dos de nuestros pacientes. Puede presentarse en forma esporádica o familiar, autosómica dominante, con alto grado de penetrancia. Pusede ser parte del síndrome de neoplasia en doctrina múltiple de tipo II, carac. terizado por cáncer tiroideo medular, feocromo. citoma e hiperparatiroidismo, y si, además, se asocia a neuromatosis múltiple se denomina de tipo JII. Estos pacientes pueden tener hábito marfanoide y presentar neuromas difusos en mucosas, que se manifiestan como nódulos visibles en la. bios, borde de lengua y bordes palpebrales (figura 1). El carcinoma medular de tiroides se ori. gina de las células $\mathrm{C}$ del tiroides $\mathrm{y}$, por tanto, secreta calcitonina. Así los niveles plasmáticos de calcitonina basales o postestimulación con calcio o pentagastrina pueden ser usados como marcadores para detectar miembros afectados en una familia antes que el tumor se manifieste clinicamente $^{12}$.

En los otros tipos de cáncer tiroideo no se mencionan antecedentes familiares relevantes; sin embargo, cuatro de los pacientes tenían pa. rientes cercanos con afecciones tiroideas variadas: bocio, tiroiditis e hipotiroidismo congénito.
En el estudio de laboratorio del cáncer tjroideo, habitualmente la función tiroidea es normal, como se observó en todos nuestros pacientes. La determinación de antícuerpos antitiroideos puede ser negativa o positiva. La presencia de anticuerpos plantea la posible concomitancia de tiroiditís y cáncer tiroideo. La relación entre ambas afecciones no está aún suficientemente clarificada.

La cintigrafía tiroidea es probablemente uno de los exámenes más útiles para el diagnóstico de cáncer tiroideo. La presencia de un área de captación baja o ausente (nódulo frio) sugiere carcinoma o adenoma ${ }^{5,7}$. Sin embargo es necesario tener presente que también se pueden encontrar imágenes cintigráficas de captación irregular o moteada, de mayor o menor extensión, característica más propia de una tiroiditis crónica. Esta situación se presenta especialmente cuando existe asociación de tiroiditis y cáncer. La ultrasonografía y la tomografía computarizada son especialmente útiles para determinar si un nódulo tiroideo es sólido o quístico.

El cáncer más frecuente del tiroides es del tipo papilar $\left(71,6 \%\right.$, en la serie de Winship) ${ }^{6}$. Sin embargo, en muchos casos, pueden encontrarse también elementos foliculares (tipo mixto). De los tumores tiroideos, $5,4 \%$ son de difícil clasificación y sólo $2,6 \%$ son carcinomas medulares en nif̂́as.

Desde el punto de vista anatomopatológico, de los nueve casos estudiados por nosotros, cuatro correspondían a carcinoma papilar. Dentro de este grupo, tres presentaron aumento de tamaño del tiroides, mientras el cuarto caso tenía tiroides normal en el examen clínico, acompañado de infiltración de tráquea, nervio recu. rrente y yugulares. Además, tres de estos pacien. tes presentaron metástasis ganglionares y tiroiditis crónica. En relación a este último hallazgo consjderamos que la biopsia por punción puede caer en zonas de tiroiditis exclusivas y postergar el diagnóstico de la neoplasia. Los dos casos de cáncer folicular observados terían bocio y uno de ellos metástasis ganglionar. De los cánceres medulares, uno se presentó como un nódulo adherido a uno de los polos superiores del tiroides, sin metástasis ganglionares ni invasión local ni a distancia; el segundo tenía compromiso de ambos lóbulos tiroideos $\mathrm{y}$, además, infiltración vascular y de nervios recurrentes.

El tratamiento del carcinoma tiroideo es fundamentalmente quirúrgico, y frente a todo nó- 
dulo, la ablación y la biopsia inmediata son imperativas. Si la histología confirma la malignidad se procederá a la resección subtotal o total, según el caso, tenierdo presente que el tumor puede ser multifocal. En todo caso, el hallazgo de carcinoma medular o de ganglioneurona es indicación de tiroidectomía total ${ }^{5}$. El yodo radiactivo $\left(I_{131}\right)$ está particularmente indicado como medio de detección de metástasis o remanente tiroideos y como agente destructor de tejido tiroideo metastásico; fundamentalmente de metástasis pulmonares. Después del tratamiento quirúrgico está indicada la terapia de sustitución con hormona tiroidea en dosis algo superiores a la físiológica, con el objetivo de obtener una completa supresión de TSH $^{5,7}$. Los pacientes deben ser controlados periódicamente observando la posible aparición de nódulos metastásicos en cuello o a distancia.

\section{RESUMEN}

Se presentan nueve niños con cáncer tiroideo; cuatro hombres y cinco mujeres, de edades entre 3 años y 16 años. En su examen físico destacaba el bocio de consistencia aumentada, frecuentemente uninodular. La función tiroidea era normal en todos los casos estudiados. La cintigrafia tiroidea reveló una zona de captación irregular o nula, motivando la biopsia. El tratamiento preferido fue la tiroidectomia total y la extirpación de los ganglios regionales cuando estaban afectados. Posteriormente se realizó terapia con hormona tiroidea en dosis frenadoras de TSH. EI estudio histológico reveló cáncer tiroideo difêrenciado en todos los casos (papilar-folicular o medular). La evolución postoperatoria fue satisfactoria, quedando tres pacientes con hjpoparatiroidismo secundario. Se hace énfasis en la importancia del diagnóstico precoz, que permite un relativo mejor pronóstico.

\section{REFERENCIAS}

1. Brujere A., David M., Joubert de Beaujere M.; Brumet-Nentigny' M.; Gilly J.; Freicon F.: Le cancer du corps thyroide chez 18 enfant. La Piesse Medicale, 1984; 10:13-18.

2. Exelby P.E. y Frazell E.L. : Carcinoma of the thyroid in children. Surg Clin North Amer 1969; 49: 249259.

3. National Concer Institute: Information for physicians or irradiation-related thyroid cancer. Cancer 1976; 26: 150-153.

4. Conrod R.A., Dobyns B.M. and Sutow W.W.: Thyroid neoplasia as late effect of exposure to radioactive ionide in fallout. JAMA 1970; 214: 316.

5. Pierson M.: Tiroides, Cap. III. En "Endoctinología Pediatrica y Crecimiento". Job Jean-Claude and Pierson M. Edi. Científico-Médica. Barcelona, I983, p. 165-169.

6. Winship T. and Roswoll R.V.: Thyroid carcinoma in ehildhood: final report on a 20-years study. Clin Proc. Child Hosp Natl Méd Ctr 1970; 26: 327 . 332 .

7. Clayton G.W.: Tumors of the Thyroid, Part V. En "Clinical Pediatrics and adolescent EndocrinoJogy". Kaplan, S.A.W.B. Saunders Co. Phil 1982; p. 118-130.

8. Fish, J. and Moore R.M.: Ectopic thyroid tissue and ectopic thyroid carcinoma: a review of the literature and report of a case. Ann Sur 1963;157: 212-217.

9. Li Velsi V.A., Perzon K.H. and Savetsky L.: Carcinoma arising in median ectopic thyroid (including thyroglosal duct tissue). Cancer 1974; 34: 1303-1313.

10. Harada $T$., Nishikawa $Y$. and Ito $K$.: Aplasia of one thyroid lobe. Am J Surg. 1972 124: 617-621.

11. Hazard J.B., Hawk W.A. and Crile G. Jr.: Medullare (solid) carcinoma of the thyroid: a clinical pathology entity. J. Clin Endocrimol 1959; 19: 152-158.

12. Lavin N.: Thiroid disorders in children. En "Manual of Endocrinology and Metabolism. Lavin Brown and Co. Boston/Toronto. 1986, p. 433-440.

13. Buckwalter J.A.. Thomas. C.G. and Freeman J.B. Is childhood thyroid cancer a lethal disease. Am Surg $1975 ; 181: 632-637$. 